\title{
Electricity Demand in South Africa: Is it Asymmetric?
}

\author{
Rangan Gupta \\ Department of Economics, University of Pretoria, Pretoria, 0002, South Africa \\ Roula Inglesi-Lotz ${ }^{*}$ \\ Department of Economics, University of Pretoria, Pretoria, 0002, South Africa \\ John W. Muteba Mwamba \\ Department of Economics and Econometrics, Faculty of Economic and Financial Sciences, \\ University of Johannesburg, Auckland Park, 2006, South Africa
}

\begin{abstract}
The electricity demand in South Africa has experienced vast changes both from a policy point of view but also due to the country's great industrialisation and urbanisation. The literature dealing with the South African electricity case, to date, has not taken into account these changes and their effect to the symmetric behaviour of the residential and industrial electricity consumers. Hence, this paper aims at examining the asymmetric behaviour of the annual South African electricity demand (total, residential and non-residential) for the period 1960 to 2012. To do so, three different tests were used: the entropy test proposed by Racine and Maasouni $(2007,2008)$, the conditional symmetry test proposed by Bai and Ng (2001), and the Triples test proposed by Randles et al. (1980). The findings showed that there is weak evidence of asymmetry, given that the null hypothesis of symmetry can only be rejected at $10 \%$ level of significance. Hence, econometric models examining the South African electricity demand during the same period are credible in their assumption of a linear data generating process.
\end{abstract}

JEL Codes: C22; Q40Keywords: Asymmetric behaviour; electricity demand; South Africa

\footnotetext{
*Corresponding author. Email: roula.inglesi-lotz@up.ac.za.
} 


\section{Introduction}

In the energy literature, models that examine the dynamics and factors of energy demand, are mostly developed assuming that the consumers' behavior exhibit symmetric responses to various shocks for example in prices and income. However, in the macroeconomic literature, the asymmetric behavior of variables has been discussed widely with specific mention on the asymmetry of prices. Tobin (1972) for example established that prices exhibit a certain sticky behavior when going down but being more flexible when going up. This behavior have specific effects to the national aggregate demand behavior (Ball and Mankiw, 1994). Similarly, energy consumers might react differently, for instance, to price cuts and price increases but also to changes above the previous maximum and below the maximum (Gately and Huntington, 2002). Additionally shocks in the country's output will possibly have asymmetric effects on electricity demand (Narayan et al. 2008a, b). Griffin and Schulman (2005) add to the discussion the concept of energy-saving technical change as a proxy of the price asymmetry notion. They conclude their argument by suggesting that future research should comprehend the levels of technical change and price shocks affecting energy consumption and how symmetric these reactions will be.

McQueen and Thorley (1993) suggest that if the series in question is asymmetric then linear forecasting models will produce inaccurate results and hence, influence policy and budgetary decisions biasedly. International energy literature (Bowden and Payne 2008; Barhelmie 2008, Pao et al., 2012; Adom and Bekoe, 2012; Bianco et al. 2013; Hazmacebi and Es, 2014) have focused on forecasting energy demand assuming symmetric reactions of demand. Presence of asymmetries however will invalidate such forecasting models. Narayan and Popp (2009) examined this behavior for the G7 countries and concluded that asymmetry does not exist for the period 1960 to 2002.

The number of studies concerning the South African electricity market has increased since 2008 when the first wave of load shedding and instability in the balance between demand and supply occurred. All the efforts in forecasting the rapidly increasing demand in South Africa (Inglesi, 2010; Inglesi and Pouris, 2010; SO (2010), CSIR (2010) and Sigauke and Chikobvu (2011)) followed the international example in assuming linear behavior of consumption. In this paper, we will examine for the first time for South Africa whether the electricity consumption exhibits characteristics of asymmetry by looking not only at the total electricity demand of the country but also separately the residential and non-residential electricity consumption. To do so, we employ three econometric tests for asymmetry: the entropy tests as proposed by Racine and Maasouni $(2007,2008)$, the conditional symmetry test as proposed by Bai and $\mathrm{Ng}$ (2001), and the triples test proposed by Randles et al. (1980) to test for asymmetry in the total, residential and non-residential electricity demand in South Africa for the period 1960 to 2012.

The structure of the paper is as follows. In Section 2, we discuss the specifics of the South African electricity market and the recent studies examining the dynamics of electricity and energy consumption in the country. Next we discuss the econometric testing processes and data, while in section 4 we discuss the empirical results. We conclude with a summary of the results and their policy implications. 


\section{The South African energy market}

The South African energy market is monopolised by the national supplier Eskom that generates approximately $95 \%$ (including 5\% imports) of the current supply (Eskom website, nd.). Eskom and the municipalities of the country are responsible for the distribution of electricity. On the demand side, South Africa's total energy consumption is currently dominated by the transport sector (37\%) and the industrial sector (32.9\%), followed by the commercial and mine users with $9 \%$ and $8 \%$ respectively in 2012 (Doe,2012). Most of the country's generating capacity emanates from coal (72.1\%) (Eskom, 2014)

The first crisis in the energy supply of South Africa was experienced in 2008. The unscheduled power cuts and load shedding had severe consequences to the energy sector and the economy as a whole. Since then, Eskom has requested and in most cases, achieved high tariff increases. Additionally, two extra power plants, Kusile and Medupi, were funded by the World Bank to assist with the mismatch between supply and demand in the country. Although planned to start operating in the beginning of 2015, this plan failed leading the country (after older power plants had to go for necessary and urgent maintenance) to a second wave of load shedding from the end of 2014.

In South Africa, the number of studies looking at the factors that affect the electricity consumption and the dynamics of the electricity demand have started increasing rapidly since 2008 (Inglesi-Lotz and Pouris, forthcoming). All the studies investigating the causal relationship between electricity (energy) growth and economic growth in the country (Odhiambo, 2009; Dlamini et al., forthcoming a, b; Kahsai et al., 2012; Al-mulali and Sab, 2012; Eggoh et al., 2011; Wolde-Rufael, 2006; WoldeRufael, 2009) assumed a linear relationship between the two. Looking at the various factors that influence the energy or electricity consumption in the country, almost all studies agreed that income and price are the main determinants but again in a linear format (Inglesi, 2010; Ziramba, 2008; Amusa et al., 2009; Inglesi and Pouris, 2010; Inglesi-Lotz and Blignaut, 2011; Louw et al., 2008; Senatla, 2011; Inglesi-Lotz, forthcoming). Inglesi-Lotz (2011) and Inglesi-Lotz (2014) looked the timevarying price elasticities of aggregate and industrial electricity consumption in South Africa, taking thus into account possible differences in the behavior of consumers from one year to another. Analysis on forecasting electricity demand in South Africa (Sigauke and Chikobvu, 2011; SO, 2010; CSIR, 2010; Inglesi, 2010; Inglesi and Pouris, 2010) might be affected by possibly wrongly assuming there is symmetry in the electricity consumption.

\section{Methodology}

The main objective of this paper is to test for conditional symmetry in South African electricity demand using three different techniques namely the entropy test (Racine and Maasoumi, 2007, 2008), the triples test (Randles et al., 1980), and the conditional symmetry test (Bai and Ng; 2001) respectively.

\section{a) Entropy Test of Symmetry}

The entropy test of asymmetry described in Maasoumi and Racine (2008) is based on the normalization of the Bhattachorya - Hellinger statistic measure of dependence $S_{p}$ given by: 
$S_{p}=\frac{1}{2} \int_{-\infty}^{+\infty}\left(f_{1}^{1 / 2}-f_{2}^{1 / 2}\right)^{2} d y$

where $f_{1}=f(y)$ is the marginal density of a continuous stationary random variable $Y_{i}$, and $f_{2}=f(\hat{y})$ that of $\widehat{Y}_{l} ; \widehat{Y}_{l}$ being a rotation of $Y_{i}$ about its mean i.e. $\widehat{Y}_{l}=-Y_{i}+2 E\left(Y_{i}\right)$. The vector $Y_{i}$ is parametrically asymmetric about the mean if $f(y) \equiv f(\hat{y})$ which corresponds to the following test of asymmetry:

$H_{0}: f(y)=f(\hat{y})$ for all $y$

To obtain an entropy version of this asymmetry test; Racine and Maasoumi $(2007,2008)$ make use of the standard Parzen kernel estimators (see Parzen, 1962) of the statistic $S_{p}$ with a specific number of bootstrap resampling based on Efron (1982)'s methodology ${ }^{1}$.

\section{b) The Triples Test}

The triples test performs a non-parametric test for symmetry of the null hypothesis that the data in the vector $Y$ comes from a symmetric distribution. The test involves examining all possible combinations of three observations (triples: $y_{i}, y_{j}, y_{k}$ ) from a sample of $N$ observations. These three observations form a right triple if the middle value is closer to the lower observation; a left triple if the middle observation is closer to the higher observation.

Following Randles et al. (1980), the triples test statistic $U$ is based on the difference between the number of right and left triples. The null hypothesis of symmetry is rejected when the number of right triples equal the number of left triples i.e. $U=0$. When the difference between the number of left and right triples is different from zero the distribution of the random variable $Y$ is said to be left skewed (number of left triples is greater than the number of right triples); or right skewed when the number of right triples is greater than the number of left triples. Formally the test statistic $U$ is normally distributed with zero mean and unit standard deviation; and is expressed as:

$U=\frac{\sqrt{N \widehat{\eta}}}{\widehat{\sigma_{\eta}}}$

where

$\hat{\eta}=\left(\begin{array}{c}N \\ 3\end{array}\right) \sum_{i<j<k} f\left(y_{i}, y_{j}, y_{k}\right)$

with

$f\left(y_{i}, y_{j}, y_{k}\right)=\frac{1}{3}\left[\operatorname{sign}\left(y_{i}+y_{j}-2 y_{k}\right)+\operatorname{sign}\left(y_{i}+y_{k}-2 y_{j}\right)+\operatorname{sign}\left(y_{j}+y_{k}-2 y_{i}\right)\right]$

where the $\operatorname{sign}(a)$ is equal to $-1,0$, and 1 for $a$ being lower, equal or greater than zero, respectively. Therefore $f($.$) can only take the values -\frac{1}{3}, 0$, and $\frac{1}{3}$.

$\hat{\sigma}_{\hat{\eta}}=\sqrt{\left(\begin{array}{c}N \\ 3\end{array}\right)^{-1} \sum_{c=1}^{3}\left(\begin{array}{l}3 \\ c\end{array}\right)\left(\begin{array}{c}N-3 \\ 3-c\end{array}\right) \hat{\zeta}_{c}}$

\footnotetext{
${ }^{1}$ The $\mathrm{R}$ codes for the implementation of this test are provided in the $n p$ package of the $\mathrm{R}$ software freely available at: http://www.r-project.org.
} 
with

$\hat{\zeta}_{c}=N^{-1} \sum_{i=1}^{N}\left[f_{1}\left(y_{i}\right)-\hat{\eta}\right]^{2}$

$f_{1}\left(y_{1}\right)=\left(\begin{array}{c}N-1 \\ 2\end{array}\right)^{-1} \sum_{j<k}, \sum_{i \neq j, j \neq k} f\left(y_{i}, y_{j}, y_{k}\right)$

$\hat{\zeta}_{2}=\left(\begin{array}{c}N \\ 2\end{array}\right)^{-1} \sum_{j<k} \sum\left[f_{2}\left(y_{j}, y_{k}\right)-\hat{\eta}\right]^{2}$

$f_{2}=\left(y_{j}, y_{k}\right)=(N-2)^{-1} \sum_{i=1}, \sum_{i \neq j \neq k, i \neq k} f\left(y_{i}, y_{j}, y_{k}\right)$

and;

$\hat{\zeta}_{3}=\frac{1}{9}-\hat{\eta}^{2}$

\section{c) Conditional Symmetry Test of Bai and $\mathrm{Ng}$}

The Bai and Ng (2001) conditional symmetry test is based on the following time series model:

$Y_{t}=h\left(\Omega_{t}, \beta\right)+\sigma\left(\Omega_{t}, \lambda\right) e_{t}$ for all $t=1,2,3, \ldots T$

where $Y_{t}=h\left(\Omega_{t}, \beta\right)$ is the conditional mean function with parameter vector $\beta ; \sigma\left(\Omega_{t}, \lambda\right)$ is the conditional variance with parameter vector $\lambda . \Omega_{t}$ is the information set at time $t$ consisting of an infinity number of lagged values of $Y_{t} . e_{t}$ is a white noise variable representing the disturbance term. Conditional symmetry is equivalent to the symmetry of the disturbance term $e_{t}$ about zero. That is $f\left(e_{t}\right)=f\left(-e_{t}\right)$ for all $e$; where $f$ is the density function of $e$.

The main idea behind Bai and $\mathrm{Ng}$ (2001) conditional symmetry test is to compare the distribution function of positive $e_{t}$ say $F_{T}^{+}(y)$ and that of $-e_{t}$ say $F_{T}^{-}(y)$. Under the null of symmetry the difference between the two empirical distribution functions should be small for all values of $y$. That is:

$\widehat{W}_{T}(y)=F_{T}^{+}(y)-F_{T}^{-}(y) \approx 0$

Bai and $\mathrm{Ng}$ (2001) show that the test statistic $C S^{+}$and $C S^{-}$are the maximum (for all $y \geq 0$ ), and minimum (for all $y \leq 0$ ) of the martingale transformation of $\widehat{W}_{T}(y)$ respectively. Their asymptotic critical values are reportedly equal to $2.78,2.21$, and 1.91 at $1 \%, 5 \%$, and $10 \%$ significance levels, respectively.

\section{EMPIRICAL RESULTS}

We use the annual data on residential, non-residential, and total electricity demand for South Africa spanning from 1960 to 2012 in order to test the null hypothesis of conditional symmetry in their respective distributions. The data are derived from two different sources: South African Energy Statistics by the National Energy Council (NEC, 1990) for the years from 1970 to 1989 and the Energy Balances by the Department of Energy (DoE, various issues) for the rest. 
Figure 1 below exhibits the evolution of the electricity demand during our sample period. Based on this Figure 1, one can see that the total electricity demand increases monotonically overtime due to consistent increase in non-residential electricity demand. The gap between residential and nonresidential electricity demand has significantly widen since the early 1970's due to rapid industrialization of the country.

Figure 1: Electricity demands: Residential, Non-residential, and Total (in 1000s GWh)

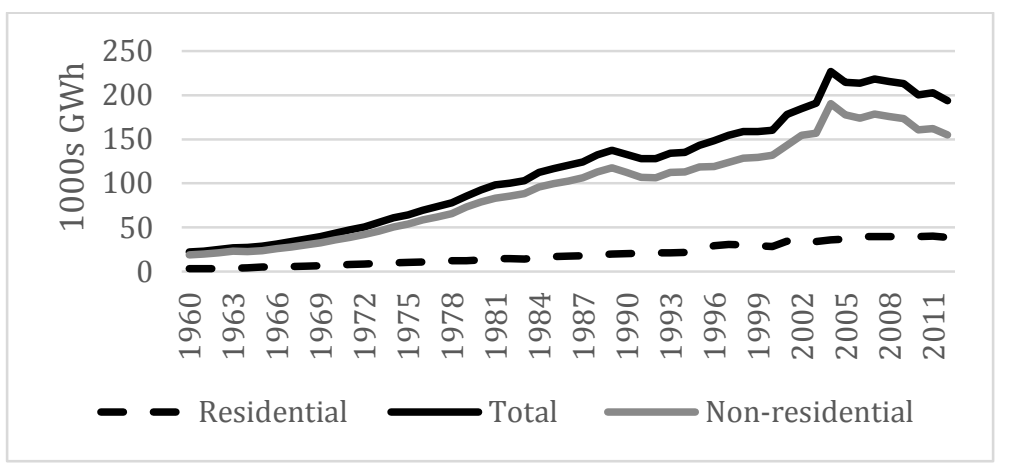

Source: NEC (1990) and DoE(various issues)

As is standard practice in time series analysis, to apply our tests of asymmetry, we will need to ensure that our three variables of concern are stationary. Given this, we not only apply standard unit root tests (Elliott et al., (DF-GLS, 1996), and Ng and Perron (NP, 2001)), but also tests with one break (Zivot and Andrews (ZA, 1992)) and two breaks (Lee and Strazicich (LS, 2003)). From the plots of the raw data, unit root tests seems to be well-justified, with two possible breaks in late 1980s and early2000s. As can be seen from Table 1, the tests applied to the natural logarithms of the variables and their first-differences, residential, non-residential and total electricity demands are all integrated of order one, i.e., I(1). 
Table 1. Unit Root Tests without and with Structural Breaks

\begin{tabular}{|c|c|c|c|c|c|c|c|c|}
\hline Variables & \multicolumn{2}{|c|}{ DF-GLS } & \multicolumn{2}{|c|}{ NP } & \multicolumn{2}{|c|}{ ZA } & \multicolumn{2}{|c|}{ LS } \\
\hline Natural Log-Levels & Constant & Constant+Trend & Constant & Constant+Trend & Constant & Constant+Trend & Constant & Constant+Trend \\
\hline Residential & 1.2477 & -0.8342 & 1.1292 & -1.659 & -1.8205 & -2.4682 & -1.8564 & -5.1892 \\
\hline Non-Residential & -0.4659 & 0.0959 & -0.8476 & 0.5905 & -1.2271 & -2.1159 & -0.986 & -3.0057 \\
\hline \multirow[t]{2}{*}{ Total } & -0.6801 & -0.8171 & -1.7937 & 0.974 & -0.9974 & -1.8675 & -0.9335 & -3.1444 \\
\hline & \multicolumn{2}{|c|}{ DF-GLS } & \multicolumn{2}{|c|}{ NP } & \multicolumn{2}{|c|}{ ZA } & \multicolumn{2}{|c|}{ LS } \\
\hline First-Differences & Constant & Constant+Trend & Constant & Constant+Trend & Constant & Constant+Trend & Constant & Constant+Trend \\
\hline Residential & $-7.3282 * * *$ & $-8.3438^{* * *}$ & $-25.4148^{* * *}$ & $-24.6986 * * *$ & $-8.6863 * * *$ & $-8.8209 * * *$ & $-8.8730 * * *$ & $-8.8378 * * *$ \\
\hline Non-Residential & $-5.1423^{* * *}$ & $-6.5138^{* * *}$ & $-23.4654^{* * *}$ & $-25.2439 * * *$ & $-7.1571 * * *$ & $-7.7848 * * *$ & $-7.0603 * * *$ & $-8.4243^{* * *}$ \\
\hline Total & $-4.7827^{* * *}$ & $-6.3265^{* * *}$ & $-32.0660 * * *$ & $-26.7882^{* * *}$ & $-6.7160 * * *$ & $-7.8834 * * *$ & $-7.3718 * * *$ & $-8.1246 * * *$ \\
\hline
\end{tabular}

Notes: ${ }^{* * *}$ indicates rejection of the null of unit root at 1 percent level of significance. 
The descriptive statistics of the growth rates are reported in Table 2; these include the mean, standard deviation, the skewness, the kurtosis and the normality tests. The mean rates of nonresidential, residential, and total demand are found to be $4.05 \%, 4.7 \%$ and $4.17 \%$ respectively.

Table 1: Descriptive Statistics:

\begin{tabular}{|l|l|l|l|l|l|l|}
\hline Variables & Mean & Std. Dev & Skewness & Kurtosis & $\begin{array}{l}\text { Jarque- } \\
\text { Bera }\end{array}$ & $\begin{array}{l}\boldsymbol{p} \text { - } \\
\text { values }\end{array}$ \\
\hline Non-residential & 0.04 & 0.05 & -0.10 & 3.76 & 1.33 & 0.51 \\
\hline Residential & 0.05 & 0.06 & 0.27 & 3.80 & 1.99 & 0.37 \\
\hline Total & 0.04 & 0.05 & -0.15 & 3.45 & 0.65 & 0.72 \\
\hline
\end{tabular}

Note: Std.Dev: Standard Deviation.

Table 1 reports similar magnitudes of variability in the demand of non-residential, residential and total electricity demands, with the residential electricity demand being slightly more volatile at $6.08 \%$. Non-residential and total demands are negatively skewed, while, the residential demand is skewed to the right. The degree of kurtosis are quite similar, with the residential demand having the highest value of 3.80 . The Jarque-Bera test confirms normality for all the three electricity demands quite overwhelmingly.

Having found unit root in the natural logarithms of the data, but having rejected the null hypothesis of the existence of unit root in the growth rates; we use these growth rates to test the asymmetric behaviour of electricity demand for residential, non-residential, and total electricity demand. Note that, we standardize the growth rates of the three electricity demands by dividing with their respective standard deviation. This allows us to compare which electricity demand is more asymmetric for a specific test statistic, in case, our tests of symmetry (reported below), end up being rejected. Standardised growth rates plotted in Figure 2 below show that the non-residential electricity demand has remain constant overtime since the early 1960. The total electricity demand is found to be mostly driven by the demand from non-residential consumers. However the growth rate in the total electricity demand has dramatically decreased since early 2000 . It became negative around 2010 and is likely to remain negative following a series of load-shedding the country has experienced in recent years. 
Figure 2: Standardised growth rates of electricity demand: Residential, Non-residential, and Total

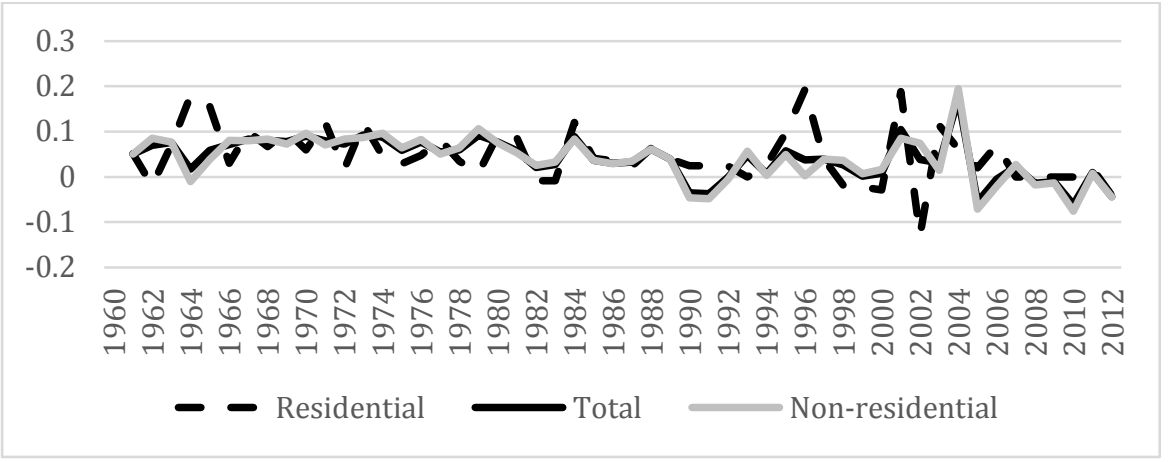

Sources: NEC (1990) and DoE (various issues)

Table 3 reports the test statistic of each of the three conditional symmetry tests namely entropy test (Maasouni; 2007, 2009), non-parametric symmetry - triples test (Randles et al. 1980) and the conditional symmetry test- Bai- $\mathrm{Ng}$ test (Bai and $\mathrm{Ng}$; 2001). Note that, since we work with (standardized) growth rates, we loose the first data point, and hence our effective sample covers the period of 1961-2012 (i.e., 52 observations).

Table 3: Test Statistic of Conditional Asymmetry Test: Ho: Symmetry

\begin{tabular}{|l|l|l|l|}
\hline & Entropy & Triples & Bai - Ng \\
\hline Non-residential & 0.2027 & -1.0977 & 1.2801 \\
\hline Residential & 0.0311 & $1.6785^{*}$ & 1.6849 \\
\hline Total & $0.0314^{*}$ & -1.4294 & 0.9192 \\
\hline
\end{tabular}

* Significance at $10 \%$ level.

The three test techniques (Entropy, Triples, and Bai-Ng) overwhelmingly accept the null hypothesis of symmetric behaviour in non-residential, residential, and total electricity demands at $1 \%$ and $5 \%$ significance levels. However at $10 \%$ significance level, both the Triples and the Entropy tests cannot accept the null hypothesis of symmetric behaviour (existence of asymmetry) in the residential and total electricity demand respectively. The asymmetric behaviour in the total electricity demand is the reflection of the asymmetry in residential electricity demand which is largely characterised by deep inequality in household consumptions between the suburbs and township locations.

\section{CONCLUSION}

The main objective of the paper was to test for asymmetry behaviour in the South African nonresidential, residential, and total electricity demand during the period between 1960 and 2013. Using three conditional symmetry tests namely the Entropy test, the Triples test, and the Bai-Ng tests; we found that the null that electricity demands exhibit symmetric behaviour, cannot be rejected at conventional levels of significance. Hence validating the use of linear econometric 
models in modelling electricity demand for policy and budgetary purposes. There is however, weak evidence of asymmetry, as the Triples and Entropy tests were able to reject the null of symmetry in the residential and total electricity demands respectively at the $10 \%$ significance level.

The prices of electricity in South Africa were comparatively low until 2008 and hence in general consumers did not have an incentive to change their consuming behaviour (Inglesi-Lotz 2011). Hence, potential asymmetric characteristics could not have been exhibited in the total electricity consumption of the country. However, the weak evidence of asymmetry in the residential electricity consumption might show the differences in the consumption between poorer rural areas and more industrialised and high-income urban consumers as well as the fact that residential consumption in South Africa is also more flexible when it comes to substitutions when prices of the chosen type of fuel increase.

All in all, this line of analysis as Narayan and Popp (2009) states "the extant literature which models electricity demand without accounting for asymmetry - or nonlinear modelling approaches- is reliable in terms of their policy implications". The findings of this study conclude that using linear tests for statistical exercises for the South African case are valid for the period up to 2012, although some weak evidence suggests that forecasting exercises particularly of the total electricity consumption, given the power of the Entropy test over the other tests of asymmetry, should be vigilant of possible asymmetry in the future.

\section{References}

Adom, P.K., Bekoe, W. (2012). Conditional dynamic forecast of electrical energy consumption requirements in Ghana by 2020: A comparison of ARDL and PAM. Energy 44(1), 367-380.

Al-mulali, U. and Sab, C.N.B.C., (2012). The impact of energy consumption and CO2 emission on the economic growth and financial development in the Sub Saharan African countries. Energy, 39: 180186.

Amusa, H., Amusa, K. and Mabugu, R. (2009). Aggregate demand for electricity in South Africa: An analysis using the bounds testing approach to cointegration. Energy Policy, 37: 4167-4175.

Bai, J., and S. Ng, (2001). A consistent test for conditional symmetry in time series models. Journal of Econometrics 103, 225-258.

Ball, L., Mankiw, N., (1994). Asymmetric price adjustment and economic fluctua- tions. The Economic Journal 104, 247-261.

Barthelmie, R.J., Murray, F., Pryor, S., (2008). The economic benefit of short term forecasting for wind energy in the UK electricity markets. Energy Policy 36, 1687-1696.

Bianco, V., Manca, O., Nardini, S. (2013). Linear regression models to forecast electricity consumption in Italy. Energy Sources, Part B: Economics, Planning and Policy 8(1), 86-93.

Bowden, N., Payne, J., (2008). Short-term forecasting of electricity prices for MISO hubs: Evidence from ARIMA-EGARCH results. Energy Economics 30, 3186-3197. 
CSIR. (2010). Forecasts for electricity demand in South Africa (2010-2035) using the CSIR sectoral regression model. Prepared for Eskom as inputs into the IRP2 process. Pretoria, South Africa.

Department of Minerals and Energy (DoE). Various issues. Aggregate energy balances. Pretoria: Department of Energy.

Dlamini, J., Balcilar, M., Gupta, R., Inglesi-Lotz, R. (forthcoming). Revisiting the causality between electricity consumption and economic growth in South Africa: A bootstrap rolling-window approach. International Journal of Economic Policy in Emerging Economics.

Dlamini, J., Balcilar, M., Gupta, R., Inglesi-Lotz, R. (forthcoming). Revisiting the causality between energy consumption and economic growth in South Africa: A bootstrap rolling-window approach. Energy sources Part B: Economics, Planning and Policy.

DoE (2012). Energy balances 2012. Department of Energy, Pretoria.

Eggoh, J.C., Bangake, C. and Rault, C. (2011). Energy consumption and economic growth revisited in African countries. Energy Policy, 39: 7408-7421.

Elliott, G., Rothenberg, T.J. and J. H. Stock (1996). Efficient tests for an autoregressive unit root, Econometrica 64, 813-836.

Eskom (2014). Factsheet. Available at: http://www.eskom.co.za/AboutElectricity/FactsFigures/Documents/CO_0007CoalSARev13.pdf.

Eskom website (nd.). Eskom Company information. Available at: http://www.eskom.co.za/OurCompany/Companylnformation/Pages/Company_Information_1.aspx

Gately, D., Huntington, H.G., (2002). The asymmetric effects of changes in price and income on energy and oil demand. The Energy Journal 23, 19-55.

Griffin, J.M., Schulman, C.T., (2005). Price asymmetry in energy demand models: a proxy for energysaving technical change? The Energy Journal 26, 1-21.

Hamzacebi, C., Avni Es, H. (2014). Forecasting the annual electricity consumption of Turkey using an optimised grey model. Energy 70(1): 165-171.

Inglesi, R. (2010). Aggregate electricity demand in South Africa: Conditional forecasts to 2030. Applied Energy, 87: 197-204.

Inglesi, R. and Pouris, A. (2010). Forecasting electricity demand in South Africa: A critique of Eskom's projections. South African Journal of Science, 106: 50-53.

Inglesi-Lotz, R. (2011). The evolution of price elasticity of electricity demand in South Africa: A Kalman filter application. Energy Policy, 3690-3696.

Inglesi-Lotz, R. (2014). The sensitivity of the South African industrial sector's electricity consumption to electricity price fluctuations. Journal of Energy in Southern Africa, 25(4): 2-9 
Inglesi-Lotz, R. and Blignaut, J.N. (2011). Estimating the price elasticity of demand for electricity by sector in South Africa. South African Journal of Economic and Management Sciences, 14: 1-17.

Inglesi-Lotz, R. and Pouris, A. (forthcoming). On the causality and determinants of energy and electricity consumption in South Africa: A review" Energy Sources, Part B: Economics, Planning, and Policy.

Inglesi-Lotz, R., Blignaut, J.N., Weideman, J.P. (forthcoming). Sectoral electricity elasticities in South Africa: Before and after the electricity supply crisis of 2008 . South African Journal of Science.

Kahsai, M.S., Nondo, C., Schaeffer, P.V., and Gebremedhin, T.G. (2012). Income level and the energy consumption-GDP nexus: Evidence from Sub-Saharan Africa. Energy Economics, 34: 739-746.

Lee, J. and M. C. Strazicich (2003). Minimum Lagrange multiplier unit root test with two structural breaks, Review of Economics and Statistics, 85(4), 1082-1089.

Louw, K., Conradie, B., Howells, M., Dekenah, M. (2008). Determinants of electricity demand for newly electrified low-income African households. Energy Policy, 36: 2812-2818.

McQueen, G., Thorley, S., (1993). Asymmetric business cycle turning points. Journal of Monetary Economics 31, 341-362.

Narayan, P., Narayan, S., Prasad, A., (2008a). A structural VAR analysis of electricity consumption and real GDP: Evidence from the G7 countries. Energy Policy 36 (7), 2765-2769.

Narayan, P., Narayan, S., Smyth, R., (2008b). Are oil shocks permanent or temporary? Evidence from crude oil and LNG production in 60 countries. Energy Economics 30, 919-936.

Narayan, P.K. and Popp, S. (2009). Can the electricity market be characterised by asymmetric behaviour? Energy Policy 37, 4364-4372.

National Energy Council (NEC). (1990). South African Energy Statistics 1950-1989. Pretoria: National Energy Council.

$\mathrm{Ng}$, S. and P. Perron (2001). Lag length selection and the construction of unit root tests with good size and power, Econometrica 69, 1519-1554.

Odhiambo, N. (2009). Electricity consumption and economic growth in South Africa; A trivariate causality test. Energy economics, 31:635-640.

Pao, H.-T., Fu, H.-C., Tseng, C.-L., (2012). Forecasting of CO2 emissions, energy consumption and economic growth in China using an improved grey model. Energy 40(1), 400-409.

Parzen, E., (1962). On estimation of a probability density function and mode. The Annals of Mathematical Statistics 3, 1065-1076.

Racine, J., and E. Maasoumi, (2007). A versatile and robust metric entropy test of time- reversibility, and other hypotheses. Journal of Econometrics 138 (2), 547-567. 
Racine, J., and E. Maasoumi, (2008). A robust entropy-based test of asymmetry for discrete and continuous processes. Econometric Reviews 28, 246-261.

Randles, R., Flinger, M., Policello, G., Wolfe, D. (1980). An asymptotically distribution-free test for symmetry versus asymmetry. Journal of the American Statistical Association 75, 168-172.

Senatla, M. (2011). Energy demand projections and relevance of income dynamics in Gauteng's residential sector. Journal of Energy in Southern Africa, 22: 31-47.

Sigauke, C., Chikobvu, D. (2011). Prediction of daily peak electricity demand in South Africa using volatility forecasting models. Energy Economics 33(5), 882-888.

SO. (2010). IRP 2010 Energy Forecast revision 2 report. Prepared for IRP2010 revision 2. Pretoria, South Africa.

Tobin, J., (1972). Inflation and unemployment. American Economic Review 62, 1-18.

Wolde-Rufael, Y. (2006). Electricity consumption and economic growth: a time series experience for 17 African countries. Energy Policy, 34: 1106-1114.

Wolde-Rufael, Y. (2009). Energy consumption and economic growth: the experience of African countries revisited. Energy economics, 31:217-234.

Ziramba, E. (2008). The demand for residential electricity in South Africa. Energy Policy, 36: 34603466.

Zivot, E., and D. W. K. Andrews (1992). Further evidence on the great crash, the oilprice shock, and the unit-root hypothesis, Journal of Business and Economic Statistics, 10(10), 251-270. 